\title{
Observations on Sambar Rusa unicolor (Cetartiodactyla: Cervidae) stags during hard and velvet stages of antler cycle in captivity
}

\author{
V. Vishnu Savanth ${ }^{1}$, P.C. Saseendran ${ }^{2}$, K.S. Anil ${ }^{3}$, V. Ramnath ${ }^{4}$, Justin Davis ${ }^{5}$ \& A. Prasad ${ }^{6}$ \\ ${ }^{1} \mathrm{PhD}$ Scholar, ${ }^{2}$ Professor and Head, ${ }^{3}$ Associate Professor, ${ }^{5,6}$ Assistant Professor, Department of Livestock Production Management, \\ ${ }^{4}$ Associate Professor, Department of Veterinary Physiology, \\ College of Veterinary and Animal Sciences, Thrissur, Kerala 680651, India \\ Email: ${ }^{1}$ vishnusavanth@rediffmail.com (corresponding author), ${ }^{2}$ sasipcs@yahoo.co.in, ${ }^{3}$ anilkundukulam@hotmail.com, \\ ${ }^{4}$ drvrnath@gmail.com
}

Date of publication (online): 26 October 2011 Date of publication (print): 26 October 2011 ISSN 0974-7907 (online) | 0974-7893 (print)

Editor: L.A.K. Singh

\section{Manuscript details:}

Ms \# 02672

Received 11 January 2011

Final received 09 September 2011

Finally accepted 15 September 2011

Citation: Savanth, V.V., P.C. Saseendran K.S. Anil, V. Ramnath, J. Davis \& A. Prasad (2011). Observations on Sambar Rusa unicolor (Cetartiodactyla: Cervidae) stags during hard and velvet stages of antler cycle in captivity. Journal of Threatened Taxa 3(10): 2128-2135.

Copyright: (c) V. Vishnu Savanth, P.C. Saseendran, K.S. Anil, V. Ramnath, Justin Davis \& A. Prasad 2011. Creative Commons Attribution 3.0Unported License. JoTT allows unrestricted use of this article in any medium for non-profit purposes, reproduction and distribution by providing adequate credit to the authors and the source of publication.

Author Details: see end of this article

Author Contribution: The work was part of the MVSc research of the first author. The co-authors guided with technical inputs for the research as well as preparation of the manuscript.

Acknowledgements: The research was funded by Kerala Agricultural University. We are thankful to The Director, Directorate of Museums and Zoos, Thiruvananthapuram and the Superintendent of State Museum and Zoo, Thrissur for providing facilities for the research. The help by Dr. Sunil, Veterinary Surgeon of the State Museum and Zoo, is also acknowledged.

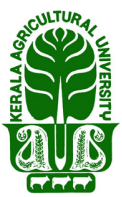

\section{(c) (i) (口)}

OPEN ACCESS | FREE DOWNLOAD
Abstract: This research was carried out at the State Museum and Zoo, Thrissur, Kerala, India from June to October, 2009. The objective was to observe and record the physical and behavioural changes in Sambar Deer Rusa unicolor stags linked to their territorial display during various stages of the breeding cycle. In total, there were 70 Sambar in the enclosure, at the commencement of the study, of which 22 were males including 16 adult stags. Six stags were selected for the study. Observations were made by focal animal sampling technique. An ethogram was devised and behavioural patterns were indicated on it. The behavioural score derived from the ethogram was significantly higher in stags in their hard antler stage when compared to the stags in the velvet stage. The stags in the hard antler stage were more massive, had bigger antlers, darker coat colour, thicker neck, larger scrotum and maintained a larger 'harem' in comparison to the velvet stage stags which preferred a rather subdued life. The most dominant stags in the hard antler stage had up to 17 female members in his territory. As the stags in velvet entered the rut season, the dominant stag had up to 19 females in his territory. The study is expected to be useful to evolve strategies to identify and reduce a few males not contributing in breeding in any particular enclosure and thus curtail expenses in management of cervids in captivity.

Keywords: Rusa unicolor, captive management, dominance hierarchy, ethogram.

\section{INTRODUCTION}

Behavioural variation in ungulate populations is an area of research, which could provide insights not only into the evolution of ungulate behaviour, but also more generally, into the evolution of the process in individual decision-making (Isvaran 2005). One such behaviour is related to breeding, particularly in the context of dominance hierarchy, factors enforcing changes in the hierarchy, the breeding cycle and maintenance of healthy populations in captive conditions.

The present study is an attempt to record dominance hierarchy visà-vis different types of behaviour associated with body conditions and breeding display in a population of Sambar Deer Rusa unicolor maintained in the State Museum and Zoo, Thrissur in Kerala, and it provides some basal information that may be needed to evolve strategies to curtail the exploding population and reduce the cost of maintenance in captivity.

\section{METHODS}

The main study was carried out over a period of four months from 
June through to October, 2009. As per the birth register at the zoo this period records a high incidence of breeding activity among Sambar. In a population of a total of 70 Sambars in the enclosure there were 22 males including 16 adult stags at the commencement of the study.

A total of six stags were selected for the study under 'focal animal sampling technique'. In this technique a single individual is observed for a specified period of time and all the instances of different categories of its behaviour are duly recorded (Martin \& Bateson 1993). On the basis of decreasing order of 'dominance hierarchy' three of the Sambars namely $\mathrm{H}_{1}, \mathrm{H}_{2}$ and $\mathrm{H}_{3}$ were in the rut or hard antler stage, and others namely $\mathrm{V}_{1}, \mathrm{~V}_{2}$ and $\mathrm{V}_{3}$ were in the later stages of velvet growth.

The factors taken into account for ranking the Sambars were the body and antler size, the ability of a stag to occupy vantage positions during feeding time, its display leading to the ability to attract a larger number of females, capacity to aggressively dictate to other stags of the herd, and carry out most of the breeding activities in the herd.

Data on behaviour of Sambar which could be linked to the breeding status of the animal were used to design the ethogram (columns 2 and 3: Table 1). An 'ethogram', which is a set of terms and descriptions of the behaviour of an animal may be comprehensive of all behaviours of a species or it may be for only one sex, age group or type of behaviour (Lehner 1987). The ethogram presented in this study is adapted with modifications over Roshin (2005) who conducted a similar study on Spotted Deer Axis axis.

During the four months of the main study, Sambars were observed for a total of 318 hours, and each animal received around 53 hours of observation. The observations were carried out from 0600 to $1800 \mathrm{hr}$ to go with the normal activity schedule of the deer as well as the zoo. The 12-hour study period was divided into twelve segments of one hour duration each and each animal was allotted two such segments every week. The stag and the time segment in which the observation was to be taken were selected randomly. The animals were observed and every activity of the deer during that particular one-hour period was recorded in the ethogram.

The number of times an animal exhibited a particular behaviour during its allotted one hour was noted. The frequency of exhibition of each behaviour was allotted a particular score as per the standard score card presented in Table 1, columns 3 to 6 (adapted and modified from Roshin 2005). The score was higher for exhibiting a behaviour directly related to breeding, and the score allotted was lower for behaviour less

Table 1. Ethogram and score chart used for behavioural data collection.

\begin{tabular}{|c|c|c|c|c|c|}
\hline & \multirow{2}{*}{ Description } & \multirow{2}{*}{ Behaviour (Diurnal) } & \multicolumn{3}{|c|}{ Breeding behaviour score / week } \\
\hline & & & 5 & 3 & 1 \\
\hline$(1)$ & $(2)$ & $(3)$ & $(4)$ & $(5)$ & (6) \\
\hline 1 & Licks its body or rubs against tree/wall. & Rubbing or grooming & $21-30$ & $11-20$ & $1-10$ \\
\hline 2 & Sniffing the lower abdomen, vulva or urine of the females. & Sniffing & $21-30$ & $11-20$ & $1-10$ \\
\hline 3 & Head with antlers are held high. & Head held high & $11-15$ & $6-10$ & $1-5$ \\
\hline 4 & Elevating its head and curling its upper lip. & Flehmen & $9-12$ & $5-8$ & $1-4$ \\
\hline 5 & Males going after the receptive female of the herd. & Chasing females & $9-12$ & $5-8$ & $1-4$ \\
\hline 6 & Mounting over the female in an attempt to mate. & Mounting & $6-12$ & $3-5$ & $1-2$ \\
\hline 7 & Fighting among the males. & Fighting & $8-11$ & $4-7$ & $1-3$ \\
\hline 8 & Thrust and ejaculation. & Service (Mating) & $5-7$ & $2-4$ & 1 \\
\hline 9 & Vocalization, mate calls & Bellowing & $5-6$ & $3-4$ & $1-2$ \\
\hline 10 & Spraying urine onto its own face, neck and antler. & Urine spraying & $5-6$ & $3-4$ & $1-2$ \\
\hline 11 & $\begin{array}{l}\text { Chasing away other males from certain areas by the superior } \\
\text { males of the herd, rubbing its body on the trees. }\end{array}$ & Territory marking & $4-5$ & $2-3$ & 1 \\
\hline 12 & Gathering food or water. & Feeding and drinking & $1-4$ & $5-8$ & $9-12$ \\
\hline 13 & Engages in rumination of food. & Rumination & $1-3$ & $4-6$ & $7-9$ \\
\hline 14 & Individual will not show any specific activity and will be lying down & Resting & $1-2$ & $3-4$ & $5-7$ \\
\hline 15 & Activities which have not been listed above & Other solitary & $9-12$ & $5-8$ & $1-4$ \\
\hline
\end{tabular}


related to breeding. To obtain the 'breeding behaviour score' for any particular stag the score recorded for each hour of observation and for each listed behaviour were added up.

The stags were observed for various changes in the physical condition and the number of females they led. The physical changes observed were purely subjective and at no point of the study were the animals restrained or immobilized as it could have led towards behavioural aberrations. The observations were mainly on the shifting of antler stages, size of the stag, changes in the coat colour, and neck and testicular circumference. The changes seen in the behavioural score of the stags were correlated to the shifting antler stages. Statistical analysis was done as described by Snedecor \& Cochran (1994).

\section{RESULTS}

Observation of the stags before, during and after the four months study period revealed that the antlers of the Sambar deer were in velvet growth for a span of 7-8 months. The complete shedding of the velvet appearance took about 5-6 days.

Stag $\mathrm{H}_{1}$ maintained a behavioural score of $42 \pm 11.73$ during the hard antler phase whereas during the velvet phase it slipped to $9.66 \pm 2.25$ (Fig. 1). The weeks which show the lowest score for $\mathrm{H}_{1}$ are between the $7^{\text {th }}$ and $9^{\text {th }}$ weeks of the study. In this case the antler was cast off during the $7^{\text {th }}$ week.

The behavioural score of stag $\mathrm{H}_{2}$ was $42.85 \pm 12.58$ during the hard antler stage and it reduced to $12.6 \pm 2.3$ during the velvet period (Fig. 2). The weeks which show the lowest score for $\mathrm{H}_{2}$ are between the $8^{\text {th }}$ and $9^{\text {th }}$ weeks. In this case the antler was cast off during the $8^{\text {th }}$ week.

Stag $\mathrm{H}_{3}$ had a behavioural score of $44 \pm 14$ during the rut season; it became 12.6 \pm 3.13 during the velvet stage (Fig. 3). The weeks which show the lowest behavioural score for $\mathrm{H}_{3}$ are between the $8^{\text {th }}$ and $10^{\text {th }}$ weeks. In this case the antler was casted off during the $8^{\text {th }}$ week.

The behavioural score of stag $\mathrm{V}_{1}$ was $23.16 \pm 12.84$ during the velvet stage, but as it entered the rut season, its score shot up to $51.81 \pm 5.54$ (Fig. 4). The weeks which show the highest score for $\mathrm{V}_{1}$ are between the $7^{\text {th }}$ and $11^{\text {th }}$ weeks. This is equal in duration as observed

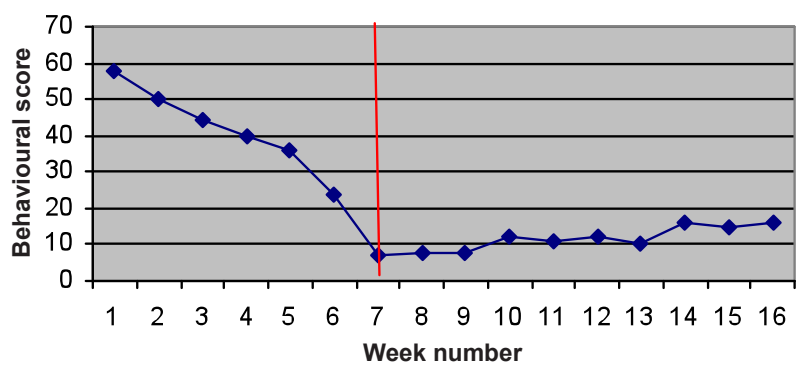

Figure 1. Behavioural scores of $\mathrm{H}_{1}$. The weeks which show the lowest score for $\mathrm{H}_{1}$ are between the $7^{\text {th }}$ and $9^{\text {th }}$ weeks. In this case the antler was cast out during the $7^{\text {th }}$ week (vertical red line). The behavioural score was $42 \pm 11.73$ during the hard antler phase whereas during the velvet phase it slipped to $9.66 \pm 2.25$.

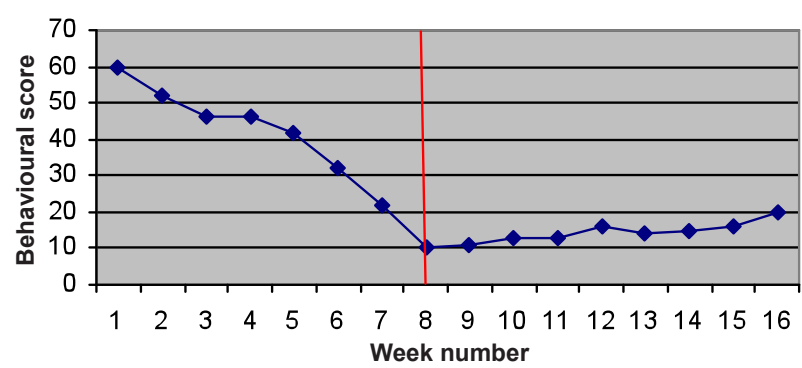

Figure 2. Behavioural scores of $\mathrm{H}_{2}$. The weeks which show the lowest score for $\mathrm{H}_{2}$ are between the $8^{\text {th }}$ and $9^{\text {th }}$ weeks In this case the antler was cast off during the $8^{\text {th }}$ week (vertical red line). The behavioural score was $42.85 \pm 12.58$ during the hard antler stage and it reduced to $12.6 \pm 2.3$ during the velvet period.

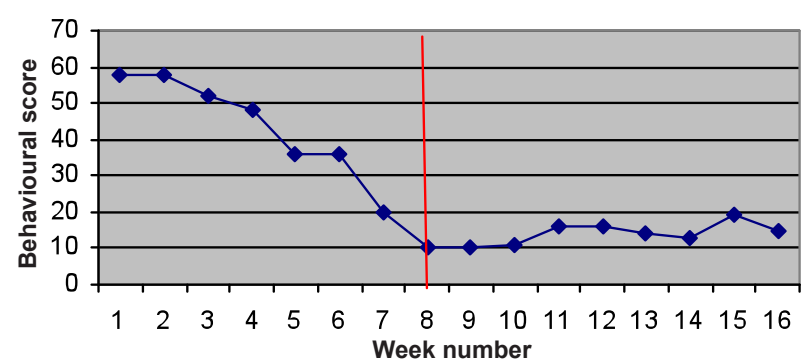

Figure 3. Behavioural scores of $\mathrm{H}_{3}$. The weeks which show the lowest score for $\mathrm{H}_{3}$ are between the $8^{\text {th }}$ and $10^{\text {th }}$ weeks In its case the antler was cast off during the $8^{\text {th }}$ week (vertical red line). The behavioural score was $44 \pm 14$ during the rut season; it became 12.6 \pm 3.13 during the velvet stage.

for V2, but it onset early. In this case the velvet was shed during the $7^{\text {th }}$ week.

Stag $V_{2}$ had a behavioural score of $24.85 \pm 13.83$ during the velvet phase; as it shifted to the hard antler stage, the score increased to $51.9 \pm 5.38$ (Fig. 5). The weeks which show the highest score for $\mathrm{V}_{2}$ are between the $8^{\text {th }}$ and $12^{\text {th }}$ weeks. This is a longer duration than 


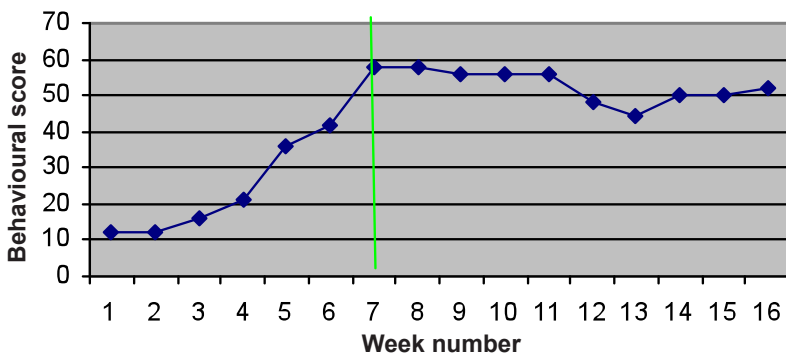

Figure 4. Behavioural scores of $V_{1}$. The weeks which show the highest score for $V_{1}$ are between the $7^{\text {th }}$ and $11^{\text {th }}$ weeks. This is equal in duration as observed for V2, but it onsets early. In this case the velvet was shed during the $7^{\text {th }}$ week (vertical green line). The behavioural score of stag $\mathrm{V}_{1}$ was $23.16 \pm 12.84$ during the velvet stage, but as it entered the rut season, its score shot up to $51.81 \pm 5.54$.

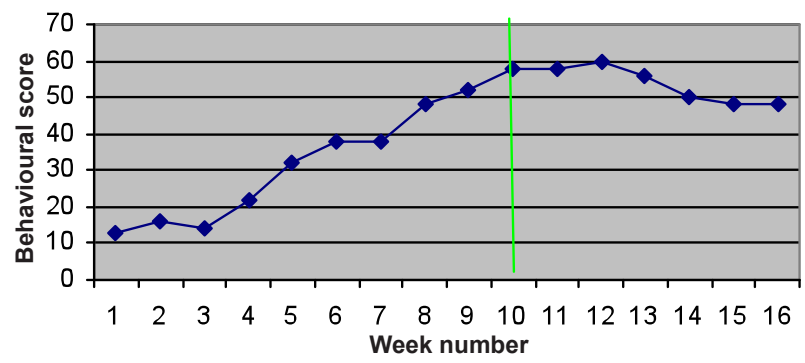

Figure 6. Behavioural scores of $V_{3}$. The three weeks which show the highest score for $V_{3}$ are the $10^{\text {th }}, 11^{\text {th }}$ and $12^{\text {th }}$ weeks. In its case the velvet was shed during the $10^{\text {th }}$ week (vertical green line). The behavioural score of $V_{3}$ was $30.33 \pm 14.76$ during the velvet antler stage, the shift to the rut took the score up to $53.75 \pm 4.83$.

that observed for V3. In this case the velvet was shed during the $8^{\text {th }}$ week.

The behavioural score of $\mathrm{V}_{3}$ was $30.33 \pm 14.76$ during the velvet antler stage, the shift to the rut took the score up to $53.75 \pm 4.83$ (Fig. 6). The three weeks which show the highest score for $\mathrm{V}_{3}$ are the $10^{\text {th }}, 11^{\text {th }}$ and $12^{\text {th }}$ weeks. In this case the velvet was shed during the $10^{\text {th }}$ week.

Figures 7 and 8 show the comparison of behavioural scores of the hard antlered and the velvet antlered groups, respectively. All three Sambars in each group follow a similar trend of behavioural score, differing, however spatially. The lowest score was reached early by $\mathrm{H}_{1}$ which is the most dominant in the group (Fig.7). The peak score is attended early by $V_{1}$ which is the most dominant in the group (Fig.8).

The behavioural scores were very high during the 'hard antler' stage for all six stags in comparison with their own scores during the 'velvet antler' period. Since Sambars are nocturnal in habit, mounting and

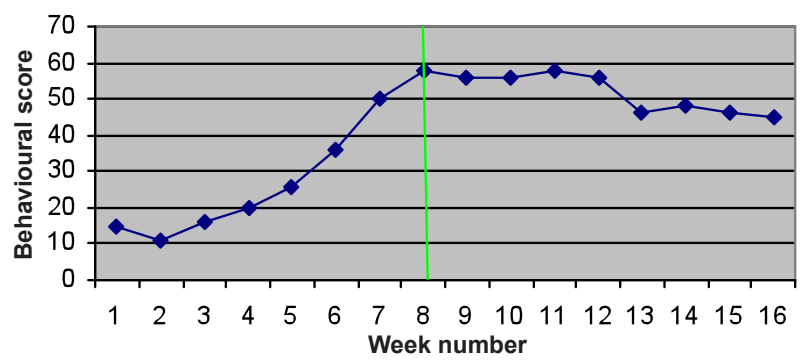

Figure 5. Behavioural scores of $V_{2}$. The weeks which show the highest score for $V_{2}$ are between the $8^{\text {th }}$ and $12^{\text {th }}$ weeks. This is a longer duration than that observed for V3. In its case the velvet was shed during the $8^{\text {th }}$ week (vertical green line). The behavioural score was 24.85 \pm 13.83 during the velvet phase. As it shifted to the hard antler stage, the score increased to $51.9 \pm 5.38$.

service could not be observed more than once, but other activities allied to breeding like chasing of females, sniffing and Flehmen's reaction were observed many times. Territorial behaviour, holding the head high, fighting, spraying urine upon its own body and face were also observed quite a few times.

The stags seemed to be in peak size and had the best body condition during the later stages of velvet growth. The good body condition was maintained through the initial phases of the rut season but, during the later stages of rut/ hard antler phase, the stags were seen in a worn out state. Deteriorated body condition was observed in those stags whose antlers were freshly cast; the stags appeared skinny, emaciated, with coat thickness much less and some of them carrying the gore wounds sustained during tussles for territory, hinds and rations. The antler regrowth stage was found to be a recuperating stage during which the stag prepared itself to face the next rut. The scrotum showed significant enlargement in the stags approaching the rut season. The coat colour was slightly darker in shade in the hard antler stages in comparison to those in other stages. The neck musculature was blown up in size during the rut season.

The stag $\mathrm{H}_{1}$ possessed the largest 'harem' followed by $\mathrm{H}_{2}$ and $\mathrm{H}_{3}$ with a membership of 17,13 and seven individuals, respectively, till they retained the hard antlers. Casting off the antlers brings in a sudden dissolve in the 'harem' size as the members prefer to join any other male that is in rut. An antler cast male or one with a newly growing antler was observed to be submissive even to the females in the herd on various occasions.

As $V_{1}, V_{2}$ and $V_{3}$ entered the rut season, $V_{1}$ formed 

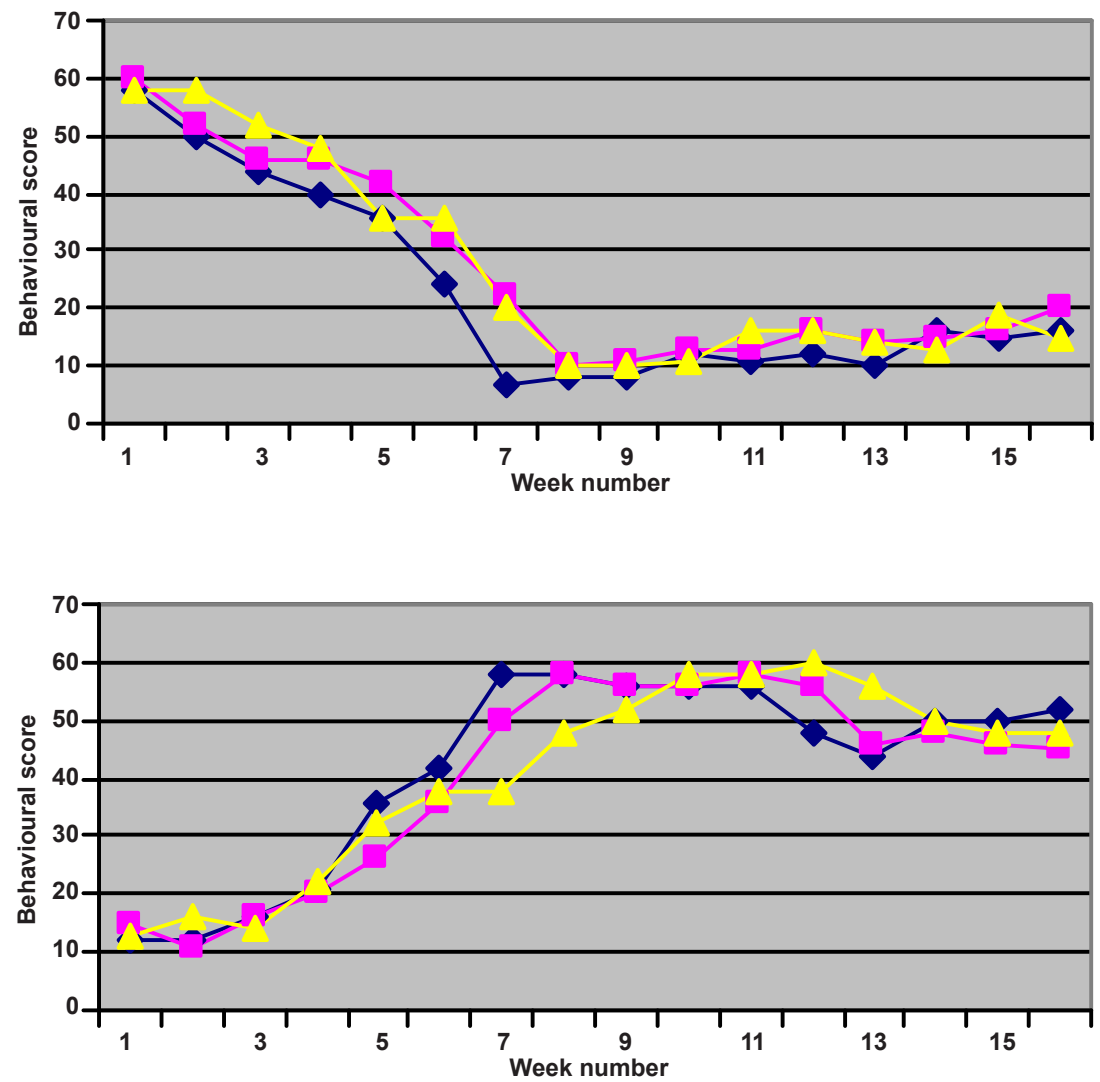

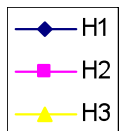

Figure 7. Comparison of behavioural scores of $\mathrm{H}_{1}, \mathrm{H}_{2}$ and $\mathrm{H}_{3}$ : All three Sambars follow a similar trend of behavioural score. The lowest score is reached early by $\mathrm{H}_{1}$ which is the most dominant in the group.

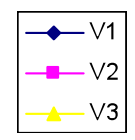

Figure 8. Comparison of behavioural scores of $\mathrm{V}_{1}, \mathrm{~V}_{2}$ and $\mathrm{V}_{3}$. All three Sambars follow a similar trend of behavioural score. The peak score is attended early by $V_{1}$ which is the most dominant in the group. the largest harem, followed by $\mathrm{V}_{3}$ and $\mathrm{V}_{2}$ not lagging far behind. These three stags enjoyed a membership of 19, 14 and 13 individuals, respectively.

\section{DISCUSSION}

The antlers are indicative of the status of breeding activity of the male and are important in dominancy display. Antler growth cycles are closely related to sexual cycles in stags and are directly attributable to variations in seasonal photoperiod influencing gonadal steroidogenic activity. Testosterone levels peak immediately before rut and it is the rapid decline in its level that causes antler casting. Antler growth occurs at a low testosterone concentration and is seen increasing when the antler growth nears completion.

The hard antlers decorate the stags for the whole rut season which lasts for about four to five months. This is followed by the antler casting stage wherein the stag may lose its antler often in a fight or by hitting against a tree or a fence. The stag may lose both the antlers on the same day or there may be a gap of 2-3 days for the second one to fall. This stage does not last long, as antler growth is a rapid continuous cycle, and the initiation of the next set of antlers would set in without much delay. Velvet shedding and antler hardening is a consequence of high testosterone levels (Woodbury \& Haigh 2007).

Quantified trends have been observed as behavioural scores in relation to antler stage, stage after shedding of antlers or transition from velvet to hard-antler stage. This shows the significance of antlers in territorial display are linked to breeding.

Findings in the case of Sambar stag in this study are similar to observations made on other deer species. Komers et al. (1997) suggested that dominance rank is the most important factor in determining the level of reproductive behaviours exhibited. As per Mulley (2007), Fallow Deer bucks will fight vigorously during the pre rut to establish dominance. Skinner \& Harrington (2003) had supportive observations that in a group of Sika Deer the activities directly associated with mating were significantly different between the territorial and non territorial groups. Pereira et al. (2005) observed that breeding behaviour of male Pampas Deer during rut was characterized by predominately ano-genital sniffing, flehmen, urine 
sniffing, chasing and mounting.

In this study, good body condition was maintained in the initial phases of the rut season but, during the later stages of rut/hard antler phase, the stags were seen in a worn out condition which is indicative of the hardships undergone during the rut for maintenance of the harem as well as the dominance quotient. Asher et al. (1987) reported that Fallow Deer bucks exhibited pronounced live weight gains over spring and summer months, to reach a peak mean weight and rapid live weight losses over the rutting period with a minimum mean live weight. Monfort et al. (1993) reported that antler length, body weight and chest girth were maximal during pre-rut in Eld's Deer which was in complete agreement with the findings of the present study.

The study showed significant enlargement of the scrotum in the stags approaching the rut season. The stags in the hard antler stage had much larger testes than those in antler cast or velvet growth stages. Monfort et al. (1993) observed maximal scrotal circumference and combined testes volume in mid winter. Georitz et al. (2003) also supported the findings with the claim that all reproductive organs were highly developed during the rut only. This finding was supported by Haigh (2007) who stressed that the scrotal circumference increased markedly and peaked at about the same time of the onset of the rutting season in Wapiti and Red Deer.

The coat colour was observed to be slightly darker in shade in hard antler stags in comparison with those in other stages. The neck musculature was blown up in size during the rut season. Similar were the findings of Gomez et al. (2006) who claimed that in case of Iberian Red Deer, neck circumference showed a time course reaching the highest values during the days of decreasing photoperiod. Blake et al. (2007) observed the neck muscles thicken during the rut season in the Reindeer also.

In a population of captive Sambar Deer, males are known to control the group led by the alpha male which is identified by its good physical appearance, sharp and long antlers, positioning at vantage points to take the major share of feed and its mates (Saseendran et al. 2003). Achieving a high social rank may be advantageous for individuals at high population densities, because dominance status may determine the priority of access to limited resources and reduce individual loss of body mass. The establishment of dominance relationships between individuals involves variable levels of aggressiveness that can be influenced by resource availability (Taillon \& Cote 2007).

The stag $\mathrm{H}_{1}$ at Thrissur Zoo possessed the largest harem followed by $\mathrm{H}_{2}$ and $\mathrm{H}_{3}$ with a membership of 17,13 and 07 individuals respectively. But the status of being the leader of the harem continued only till they retained the antlers, the casting of antlers by these males and the coming to rut of the till then velvet stags lead to a large dropout in the harem membership of the former stags who preferred to join the harems of $V_{1}$, $\mathrm{V}_{2}$ and $\mathrm{V}_{3}$. Among these stags, $\mathrm{V}_{1}$ owned the largest harem, followed by $\mathrm{V}_{3}$ and $\mathrm{V}_{2}$. The mentioned stags enjoyed a membership of 19,14 and 13 individuals respectively.

Fraser \& Broom (1997) avowed that the strongest stags are able to command the largest 'harems and enjoy the most copulation which was supportive of the results of the present study. McElligott et al. (2001) reported that larger mature Fallow bucks have advantages over other males when competing for mating. Yoccoz et al. (2002) claimed that prime-aged males are most often the harem holders among Red Deer.

Observations made by Semiadi et al. (1994) on Rusa unicolor maintained in captivity at Flock House Agricultural Centre, Bulls, Manawatu, New Zealand, indicated that although the dominant rutting Sambar stag collected a harem, the dominant stag displayed a high degree of tolerance toward the presence of other stags in hard antler within the harem.

Even though the hormonal and the reproductive cycle follow different patterns in case of seasonal temperate deer and the non seasonal tropical deer, the behavioural and the physical observations were quite similar. Only difference was that there were males in rut throughout the year and births were taking place at any time of the year unlike the temperate deer which breed only during a particular season. The adversaries caused by the overactive deer in rut season in terms of attack on fellow members or the animal keepers and on road encounters in case of wild deer will be present throughout the year, only consolation being that not every male deer will be in rut at the same time unlike the deer from temperate countries. 


\section{REFERENCES}

Asher, G.W., A.M. Day \& G.K. Barrell (1987). Annual cycle of live weight and reproductive changes of farmed male fallow deer (Dama dama) and the effect of daily oral administration of melatonin in summer on the attainment of seasonal fertility. Journal of Reproduction and Fertility 79: $353-362$.

Blake, J.E., J.E. Rowell \& M.P. Shipka (2007). Reindeer Reproductive Management. pp. 970-974. In: Youngquist, R.S. \& W.R. Threlfall (ed.). Current Therapy in Large Animal Theriogenology - 2nd Edition. Saunders Elsevier Inc., St. Louis, Missouri.

Fraser, A.F. \& D.M. Broom (1997). Farm Animal Behaviour and Welfare - 3rd Edition. CAB International, New York, $437 \mathrm{pp}$.

Gomez, J.A., A.J. Garcia, T.L. Castillejos \& L. Gallego (2006). Effect of advancing births on testosterone until 2.5 years of age and puberty in Iberian Red Deer (Cervus elaphus hispanicus). Animal Reproduction Science 96: 79-88.

Haigh, J.C. (2007). Reproductive Anatomy and Physiology of male Wapiti and Red Deer, pp. 932-936. In: Youngquist, R.S. \& W.R. Threlfall (ed.). Current Therapy in Large Animal Theriogenology - 2nd Edition. Saunders Elsevier Inc., St. Louis, Missouri.

Isvaran, K. (2005). Variation in male mating behaviour within ungulate populations: patterns and processes. Current Science 89(7): 1192-1199.

Komers, P.E., C. Pelabon \& D. Stenstrom (1997). Age at first reproduction in male fallow deer: age-specific versus dominance-specific behaviours. Behavioural Ecology 8: 456-462.

Lehner, P.N. (1987). Design and execution of animal behaviour research: An overview. Journal of Animal Science 65: 1213-1219.

Martin, P. \& P. Bateson (1993). Measuring Behaviour: An Introductory Guide - 2nd Edition. Cambridge University Press, Cambridge, UK, 222pp.

Mc Elligott, A.G., M.P. Gammell, H.C. Harty, D.R. Paini, D.T. Murphy, J.T. Walsh \& T.J. Hayden (2001). Sexual size dimorphism in fallow deer (Dama dama): do larger, heavier males gain greater mating success? Behavioural Ecology and Sociobiology 49: 266-272.

Monfort, S.L., J.L. Brown, M. Bush, T.C. Wood, C. Wemmer, A. Vargas, L.R. Williamson, R.J. Montali \&
Author Details: V.V. SAVANTH is pursuing his $\mathrm{PhD}$ on non human primate reproduction. P.C. SASEENDRAN and K.S. ANIL are working on hormonal population control in non human primates, healthcare and management of captive elephants and human-elephant conflict mitigation. V. RAMNATH is undertaking research on stress physiology and antioxidants, cancer biochemistry, molecular biology, tumour immunology, radio biology and animal cell culture technology. Justin DAvis is delving to find managemental interventions to improve dairy farming. A. PRASAD is working to explore climatological adaptation in mammals
D.E. Wildt (1993). Circannual inter-relationships among reproductive hormones, gross morphometry, behaviour, ejaculate characteristics and testicular histology in Eld's Deer Stags (Cervus eldi thamin). Journal of Reproduction and Fertility 98: 471-480.

R.C. (2007). Reproductive management of fallow pp. 952-964. In: Youngquist, R.S. \& W.R. Threlfall (eds.). Current Therapy in Large Animal Theriogenology 2nd Edition. Saunders Elsevier Inc., St. Louis, Missouri.

Seasonal changes in fecal testosterone concentrations and their relationship to the reproductive behaviour, antler cycle and grouping patterns in free-ranging male Pampas Deer (Ozotoceros bezoarticus bezoarticus). Theriogenology 63: 2113-2125. University, Thrissur.

Saseendran, P.C., A. Naser \& C. Sunilkumar (2003). Dominance and activity pattern of captive alpha stag of sambar deer population. Proceedings of $28^{\text {th }}$ Conference of Ethological Society of India; Tamil Nadu Agricultural

Semiadi, G., P.D. Muir \& T.N. Barry (1994). General biology of Sambar Deer (Cervus unicolour) in captivity. New Zealand Journal of Agricultural Research 37: 79-85.

inner, J.D. \& H. Harrington (2003). Mate choice in Sika Journal 56(12): 616-617.

Snedecor, G.W. \& W.G. Cochran (1994). Statistical Methods. 10th edition. IBH Publishing Company, Calcutta.

(2007). Social rank and winter forage quality affect aggressiveness in White-tailed Deer fawns. Animal Behavavior 74: 265-275.

reproduction, pp. 977-981. Youngquist, R.S. \& W.R. Threlfall (eds.)., In: Current Therapy in Large Animal Theriogenology - 2nd Edition. Saunders Elsevier Inc., St. Louis, Missouri.

(2002). Age and density dependent reproductive effort in male red deer. Proceedings of Royal Society London 269(B): 1523-1528. 


\section{EDITORIAL COMMENTS:}

Sambar Rusa unicolor and the Spotted Deer Axis axis are two common species of deer maintained in captive facilities in India. The paper by Savanth et al. on captive sambar of Thirssur presents two points that are noteworthy-about the breeding season in Sambar and a suggestion to the management for maintaining breeding population that ensures sound breeding, safety of animals and economy in cost of maintenance.

Literature indicates that breeding by natural and introduced population of Sambar is widespread through the year, and it is also known in general that in protracted captive populations the breeding activities may get prolonged. Peak calving in Sambar in the zoo at Thrissur is June to October, when all behaviour related to rutting, territorial displays, etc. were also recorded for publication.

Sankar \& Acharya (2004) have reviewed the details about sambar. The peak rutting season of Sambar occurs between October and December (Lydekker 1916; Schaller 1967). Sankar (1994) reported from Sariska in Rajasthan of western India that there the Sambars are in peak rut in winter, when all the stags carried antlers. For Nepalese populations of Sambar, Mishra (1982) reported peak calving time as close to the monsoon season or June-July. Semiadi et al. (1994) reported calving by a semi-domesticated herd of Sambar in Manawatu, New Zealand (40 $14^{\prime}$ 'S \& 175016'E) from January to November, with a peak in April/May.

In Similipal Tiger Reserve, Orissa, eastern India, the main breeding season for sambar is the rainy season, i.e., SeptemberOctober, and the frequency of sighting very young fawns is very high from the last week of March to the end of April. Occasionally, discarded full-grown embryonic fawns have been seen at abandoned Akhand Shikar camps. This confirms that peak calving season in Sambar coincides around the time 'Akhand Shikaar' takes place. This type of shikar is a traditional practice of mass hunting of wild animals by tribal people in Similipal which the entire district administration gears up to thwart.

During the breeding season the male Sambar exhibits lekking and attracts nearby females. Territory concept in Sambar is not rigid. For aggregation of females 'harem' is a loosely used term. The aggregations dissolve or change when a particular hierarchical structure changes. During such transition in hierarchical status male-male fight is common.

These bits of information, read with information from wild populations confirm that calving in Sambar, peaks seasonally, but the species mate and reproduce round the year. Unplanned or unrestricted breeding of deer, and allowing too many male deer to remain in one enclosure are likely to increase the cost of maintenance, and create problems of congestion and intra-specific fights which may be fatal.

The availability of the choice of more numbers of male deer in a population is one of the factors for ensuring better progeny. In a population in the wild because of the process of natural selection and survival of the fittest, maintenance of a healthy and stable population is a natural order, but in captivity a manager has to decide the process towards this goal through appropriate selection, segregation and environment enrichment. Timing of segregation is important and a site-specific knowledge on breeding behaviour is necessary for the manager. Therefore, research towards ethological records on exhibited species should always be encouraged.

Mishra, H. R. (1982). The ecology and behaviour of Chital Axis axis in the Royal Chitawan National Park, Nepal, with comparative studies of Hog Deer Axis porcinus, Sambar Rusa unicolor and Barking Deer Muntiacus muntjak. Unpublished PhD Thesis, University of Edinburgh, Edinburgh, United Kingdom.

Sankar, K. (1994). The ecology of three large sympatric herbivores (chital, sambar and nilgai) with special reference for reserve management in Sariska Tiger Reserve, Rajasthan. PhD Thesis. University of Rajasthan, Jaipur.

Sankar, K. \& B. Acharya (2004). Sambar, pp. 163-170. In: Ungulates of India. Envis: Wildlife and Protected Areas. Vol.7, No.1. Wildlife Institute of India, 448pp.

Schaller, G.B. (1967). The Deer and the Tiger: A Study of Wildlife in India. The University of Chicago Press, Chicago, 370pp.

Lydekker, R. (1916). Wildlife of the World. Vol.II. Rowland Ward Ltd., London, U.K. 